\title{
A cross-sectional study on trans-fatty acids and risk markers of CHD among middle-aged men representing a broad range of $\mathrm{BMI}$
}

\author{
Birgit M. Nielsen ${ }^{1 *} \dagger$, Marie M. Nielsen ${ }^{1} \dagger$, Marianne U. Jakobsen ${ }^{2}$, Carina J. Nielsen ${ }^{1}$, Claus Holst ${ }^{1}$, \\ Thomas M. Larsen ${ }^{3}$, Nathalie T. Bendsen ${ }^{3}$, Anette Bysted ${ }^{4}$, Torben Leth ${ }^{4}$, David M. Hougaard ${ }^{5}$, \\ Kristin Skogstrand ${ }^{5}$, Arne Astrup ${ }^{3}$, Thorkild I. A. Sørensen ${ }^{1}$ and Tine Jess ${ }^{1}$ \\ ${ }^{1}$ Institute of Preventive Medicine, Copenhagen University Hospitals, Copenhagen Capital Region, Øster Søgade 18, DK-1357 \\ Copenhagen K, Denmark \\ ${ }^{2}$ Department of Clinical Epidemiology, Aarhus University Hospital, Aalborg, Denmark \\ ${ }^{3}$ Department of Human Nutrition, Faculty of Life Sciences, University of Copenhagen, Denmark \\ ${ }^{4}$ Division of Food Chemistry, The National Food Institute (DTU Food), Technical University of Denmark, DK-2860 Søborg V, \\ Denmark \\ ${ }^{5}$ Department of Clinical Biochemistry and Immunology, Statens Serum Institute, Copenhagen S, Denmark \\ (Received 29 August 2010 - Revised 17 January 2011 - Accepted 19 February 2011 - First published online 18 May 2011)
}

\section{Abstract}

Intake of trans-fatty acids (TFA), especially industrially produced TFA (I-TFA), has been associated with the risk of CHD through influence on serum lipid levels. Other causal pathways remain less investigated. In the present cross-sectional study of middle-aged men representing a broad range of BMI, the association between intake of TFA, I-TFA and ruminant TFA (R-TFA) and obesity-associated risk markers of CHD was assessed. The study comprised 393 Danish men (median age 49 years) with a median BMI of $28 \cdot 4 \mathrm{~kg} / \mathrm{m}^{2}$. Intake of TFA was estimated based on $7 \mathrm{~d}$ dietary records, whereas outcomes of interest (waist circumference, sagittal abdominal diameter, percentage of truncal fat, C-reactive protein, IL-6, blood lipids, blood pressure, HbA1c and insulin sensitivity index) were obtained through clinical examination. The associations were assessed by linear regression analysis. The median intake of total TFA among the 393 men was $1.3 \mathrm{~g} / \mathrm{d}$, covering a daily I-TFA intake of $0.4 \mathrm{~g}(10-90$ th percentile $0 \cdot 0-1 \cdot 0)$ and R-TFA intake of $0 \cdot 9 \mathrm{~g}(10-90$ th percentile $0 \cdot 4-1 \cdot 8)$. Intake of these amounts of TFA showed no significant associations with abdominal fatness, inflammatory markers, blood lipids, blood pressure and insulin homeostasis. Among middle-aged men with a generally low intake of TFA, neither I-TFA nor R-TFA was significantly related to obesity-associated risk markers of CHD. The decreased average intake of I-TFA in Denmark since 1995 is suggested to effectively prevent occurrence of the adverse metabolic changes and health consequences, which have formerly been observed in relation to, especially, I-TFA intake.

Key words: Trans-fatty acids: CHD: Abdominal obesity: Inflammation: Blood lipids: Insulin sensitivity

Epidemiological studies have suggested a positive association between intake of trans-fatty acids (TFA) from partially hydrogenated vegetable oil and the risk of $\mathrm{CHD}^{(1)}$. These findings have resulted in a restriction of the content of industrially produced TFA (I-TFA) in manufactured food in some Western countries, including Denmark, whereas in several other countries, popular foods such as fast food, biscuits, cakes, wafers and popcorn still contain high amounts of I-TFA ${ }^{(2)}$.

The intake of I-TFA has been suggested to be more important than intake of SFA in predicting the risk of $\mathrm{CHD}^{(3)}$. Evidence suggests that I-TFA intake may result in altered lipid profiles (increased LDL-cholesterol and TAG and decreased HDL-cholesterol $)^{(4,5)}$. Also, a study in monkeys has suggested that I-TFA induces abdominal obesity ${ }^{(6)}$, which could hypothetically affect insulin sensitivity and plasma lipids. However, deposition of abdominal fat was not affected by TFA although LDL-cholesterol increased and HDL decreased in a short-term intervention study in healthy overweight postmenopausal women ${ }^{(7)}$. Furthermore, I-TFA has been observed to be associated with endothelial dysfunction, systemic inflammation and insulin resistance, although evidence is conflicting ${ }^{(1,8)}$. In contrast to I-TFA, the chemically distinct ruminant TFA (R-TFA) present in products from cow, calf, lamb and goat has either not been associated with or

Abbreviations: I-TFA, industrially produced trans-fatty acids; OGTT, oral glucose tolerance test; R-TFA, ruminant trans-fatty acids; TFA, trans-fatty acids; WC, waist circumference.

* Corresponding author: B. M. Nielsen, fax +4533 3242 40, email bn@ipm.regionh.dk

†B. M. Nielsen and M. M. Nielsen are contributed equally to the study. 
has been inversely associated with the risk of $\mathrm{CHD}^{(9)}$. However, two randomised controlled trials have found that high R-TFA intakes $(10 \cdot 2 \mathrm{~g} / 10 \cdot 5 \mathrm{MJ}$ and $11-12 \mathrm{~g} / \mathrm{d}$, respectively) have an unfavourable impact on plasma lipids ${ }^{(10,11)}$, whereas a moderate intake of R-TFA $(4 \cdot 2 \mathrm{~g} / 10 \cdot 5 \mathrm{MJ})^{(11)}$ seemed to have a minor or even neutral effect. The health effect of I-TFA and R-TFA does not seem to differ.

Earlier studies on CHD risk markers have typically been based on relatively high intakes of I-TFA ${ }^{(12)}$, and may therefore not reflect the normal average intake among persons even in countries without restrictions. The intake of I-TFA in the Danish population dropped to a level of $0.5-1 \mathrm{~g} / \mathrm{d}$ between 1995 and 2003, until the Danish legislation effectively eliminated food products containing I-TFA ${ }^{(9,13)}$. The health consequences of a relatively low intake of I-TFA remain uncertain.

The aim of the present study was to investigate whether variations in the intake of total TFA, I-TFA and R-TFA - during the period before the legislation in Denmark - were associated with obesity-associated risk markers of CHD (abdominal fat deposition, low-grade systemic inflammation, lipid profile, blood pressure and glucose homeostasis) among middle-aged Danish men representing a broad range of BMI.

\section{Experimental methods}

\section{Study population}

The present study population derives from a population of 362200 Danish men, registered at the mandatory draft boards from 1943 to 1977. Among these, two groups were manually selected: a random $1 \%$ sample of all men ( $n$ 3601) and all obese men (with a BMI $\geq 31 \mathrm{~kg} / \mathrm{m}^{2}, n$ 1930) ${ }^{(14-16)}$. This sampling technique was carried out to obtain a study population, which enabled the study of a much wider range of BMI than usual. Half of the random sample (reduced for economical and logistic reasons) and all obese subjects were followed repeatedly until the last follow-up study conducted between 1998 and 2000, in which all subjects below 65 years, who reported to be healthy and receiving no regular medication, were included $(n 557)^{(17)}$. In addition to a thorough clinical examination at follow-up, 394 subjects had completed a $7 \mathrm{~d}$ dietary record. One subject was excluded due to an energy intake below $2000 \mathrm{~kJ} / \mathrm{d}$, hence leaving 393 subjects with dietary variables recorded at a given point during 1998-2000 available for the present study.

The present study was conducted according to the guidelines laid down in the Declaration of Helsinki, and all procedures involving human subjects were approved by the Danish Surveillance Agency and the regional Ethics Committee. Written informed consent was obtained from all subjects.

\section{Intake of trans-fatty acids}

Extraction of information on dietary intake from $7 \mathrm{~d}$ dietary records has been described previously ${ }^{(18)}$. Total energy intake was calculated from the foods' content of protein $(17 \mathrm{~kJ} / \mathrm{g})$, carbohydrate $(17 \mathrm{~kJ} / \mathrm{g})$, fat $(38 \mathrm{~kJ} / \mathrm{g})$ and alcohol $(30 \mathrm{~kJ} / \mathrm{g})$.
The specific content of I-TFA in food products was estimated based on analyses of several samples of foods containing I-TFA sold in Danish retail during years $1995-2003^{(19-23)}$. To determine the most reliable estimates of I-TFA in the study period, a linear decrease in mean I-TFA content from 1995 to 2003 was assumed. Since I-TFA was out of Danish household margarine in 1999, but still present in shortenings used in the food industry ${ }^{(20,23)}$, an average value of $5.59 \mathrm{~g} \mathrm{I-TFA} / 100 \mathrm{~g}$ shortening (weighted after the sale of different categories of shortenings and corrected for water content and the $20 \%$ cis/trans overlap between peaks in capillary $\mathrm{GC}^{(20)}$ ) was used to estimate I-TFA content. A weighed division between home-made (50\%) and ready-made foods ( $50 \%$ ) was applied.

Calculation of R-TFA content in distinct food products was based on analyses of the R-TFA content in butter ${ }^{(24)}$ and ruminant meat cuts ${ }^{(25)}$. The mean content of R-TFA in butterfat was found to be $4.48 \mathrm{~g} / 100 \mathrm{~g}$, inclusive of conjugated linoleic acid, and was considered representative of milk fat in dairy products and in composite products containing milk fat ${ }^{(24)}$. Conjugated linoleic acid was not included in the mean values of R-TFA in meat ${ }^{(25)}$. The amount of total TFA was calculated by adding together the contents of I-TFA and R-TFA.

\section{Outcome assessment}

Anthropometric measurements. The present weight and height were measured as described earlier ${ }^{(26)}$. Abdominal fat distribution was determined by (1) waist circumference (WC) measured according to the WHO standard ${ }^{(27)}$, (2) sagittal abdominal diameter, measured as the maximal distance between the top of the examination table and a spirit level horizontally placed above the abdomen at the level of the iliac crest (in the expiration phase) and (3) truncal fat mass determined from measurements of body composition by dual-energy X-ray absorptiometry scans with a diagonal line passing through the middle of the femoral neck separating the lower body and truncal regions. Truncal fat mass in percentage of total tissue mass was calculated as: $100 \times$ fat tissue mass $(\mathrm{g}) /($ lean tissue mass $(\mathrm{g})+$ fat tissue mass $(\mathrm{g})+$ bone mineral content $(\mathrm{g}))^{(28)}$. The subjects were categorised as being normal weight, overweight and obese according to the WHO classification ${ }^{(29)}$.

\section{Blood lipids, inflammatory markers, glucose homeostasis and blood pressure}

Blood samples for measurements of blood lipids and inflammatory markers were obtained in the morning after an overnight $12 \mathrm{~h}$ fast. Total cholesterol, TAG and HDL-cholesterol were measured in whole blood samples. LDL-cholesterol was calculated from the Friedewald equation:

LDL-cholesterol $=$ total cholesterol - HDL-cholesterol

$$
+(\mathrm{TAG} / 2 \cdot 2)
$$

excluding measurements with TAG $>4 \mathrm{mmol} / \mathrm{l}^{(30)}$. C-reactive protein was measured by ELISA ${ }^{(31)}$ and IL- 6 was measured by Luminex xMAP technology ${ }^{(32)}$. 
HbA1c was measured and an oral glucose tolerance test (OGTT) was performed ${ }^{(33)}$. The latter was used for calculation of the composite whole-body insulin sensitivity index, defined according to Matsuda \& DeFronzo as ${ }^{(34)}$ :

(10 000/(baseline plasma glucose $\times$ baseline serum insulin

$$
\begin{aligned}
& \times \text { mean plasma glucose during the OGTT } \\
& \times \text { mean serum insulin during the OGTT })^{1 / 2} \text { ). }
\end{aligned}
$$

Blood pressure was measured with a digital blood pressure meter and a mean value of three consecutive measurements was calculated.

\section{Potential confounders}

Based on a review of the literature, the following potential confounders were included: age (years), self-reported smoking status (stated as present smoker or non-smoker), selfreported leisure-time physical activity (stated as almost passive, light activity $2-4 \mathrm{~h}$, light activity $>4 \mathrm{~h}$ or medium $2-4 \mathrm{~h}$ and hard activity $)^{(28)}$, alcohol consumption $(\mathrm{g} / \mathrm{d})$, dietary fibre $(\mathrm{g} / \mathrm{d})$, total fat $(\mathrm{g} / \mathrm{d})$, SFA $(\mathrm{g} / \mathrm{d})$ and PUFA $(\mathrm{g} / \mathrm{d})$. After exclusion of subjects for whom information on one or more potential confounder was missing, the final population consisted of 386 subjects.

Table 1. Dietary intake, age, BMI, level of physical activity and selected risk factors of CHD among Danish men representing a broad range of BMI

\begin{tabular}{|c|c|c|c|c|c|c|}
\hline & \multicolumn{2}{|c|}{ Pooled group ( $n$ 393) } & \multicolumn{2}{|c|}{ Random sample ( $n$ 232) } & \multicolumn{2}{|c|}{ Juvenile obese ( $n$ 161) } \\
\hline & Median & 10-90th Percentile & Median & 10-90th Percentile & Median & 10-90th Percentile \\
\hline Age (years) & 49 & $42-57$ & $50^{*}$ & $42-58$ & 47 & $42-54$ \\
\hline Current BMI $\left(\mathrm{kg} / \mathrm{m}^{2}\right)$ & $28 \cdot 4$ & $22 \cdot 3-39.5$ & $25 \cdot 4^{*}$ & $21 \cdot 9-30 \cdot 1$ & 34.7 & $29 \cdot 0-43 \cdot 4$ \\
\hline \multicolumn{7}{|l|}{ Dietary intake } \\
\hline Energy $\left(\mathrm{kJ} \times 10^{3}\right)$ & $10 \cdot 1$ & $7 \cdot 0-13 \cdot 7$ & $10 \cdot 2^{*}$ & $7 \cdot 6-13 \cdot 7$ & 9.5 & $6 \cdot 3-13 \cdot 7$ \\
\hline Protein $(\mathrm{g} / \mathrm{d})$ & $90 \cdot 2$ & $64 \cdot 7-123 \cdot 4$ & $90 \cdot 8$ & $67 \cdot 6-123 \cdot 2$ & $89 \cdot 3$ & $57 \cdot 9-126 \cdot 4$ \\
\hline Carbohydrate $(\mathrm{g} / \mathrm{d})$ & 253.0 & $169 \cdot 0-369 \cdot 0$ & 252.0 & $180 \cdot 0-368 \cdot 0$ & $257 \cdot 0$ & $163 \cdot 0-373 \cdot 0$ \\
\hline Fibre $(g / d)$ & $21 \cdot 1$ & $13 \cdot 6-31 \cdot 8$ & $21 \cdot 1$ & $13 \cdot 6-31 \cdot 8$ & $20 \cdot 9$ & $13 \cdot 8-31 \cdot 7$ \\
\hline Alcohol (g/d) & $20 \cdot 0$ & $0.0-63.5$ & $27 \cdot 2^{\star}$ & $3 \cdot 4-68 \cdot 0$ & $11 \cdot 7$ & $0 \cdot 0-46 \cdot 3$ \\
\hline Fat $(g / d)$ & 84.7 & $55 \cdot 0-125 \cdot 5$ & $88 \cdot 2^{*}$ & $62.9-121.5$ & 80.4 & $47 \cdot 6-126 \cdot 5$ \\
\hline SFA & $35 \cdot 2$ & $21 \cdot 7-53 \cdot 4$ & $36 \cdot 6^{\star}$ & $24 \cdot 6-53 \cdot 3$ & 33.1 & $19 \cdot 3-55 \cdot 0$ \\
\hline Total TFA & 1.3 & $0.6-2.5$ & 1.4 & $0.7-2.5$ & $1 \cdot 2$ & $0.5-2.5$ \\
\hline I-TFA & 0.4 & $0.0-1.0$ & $0.4^{*}$ & $0 \cdot 1-1 \cdot 0$ & 0.3 & $0.0-0.9$ \\
\hline R-TFA & 0.9 & $0.4-1.8$ & 0.9 & $0.5-1.7$ & 0.9 & $0.3-1.7$ \\
\hline Protein (E\%) & $15 \cdot 6$ & $12 \cdot 8-18 \cdot 7$ & $15 \cdot 4^{*}$ & $12 \cdot 6-18 \cdot 5$ & $15 \cdot 9$ & $12 \cdot 9-19 \cdot 2$ \\
\hline Carbohydrate (E\%) & 43.4 & $35 \cdot 6-52 \cdot 5$ & $42 \cdot 2^{*}$ & $34.9-50.9$ & $45 \cdot 2$ & $37.8-53.9$ \\
\hline Alcohol (E\%) & $6 \cdot 1$ & $0.0-16.7$ & $8 \cdot 2^{*}$ & $0.9-18.4$ & 3.8 & $0.0-14.3$ \\
\hline Fat $(E \%)$ & $32 \cdot 8$ & $26 \cdot 3-38 \cdot 5$ & 32.9 & $27 \cdot 1-38 \cdot 4$ & 32.5 & $25 \cdot 7-38 \cdot 7$ \\
\hline SFA & $13 \cdot 6$ & $10 \cdot 3-16 \cdot 8$ & $13 \cdot 6$ & $10 \cdot 4-16 \cdot 8$ & 13.7 & $10 \cdot 1-16 \cdot 7$ \\
\hline Total TFA & 0.5 & $0.3-0.8$ & 0.5 & $0.3-0.8$ & 0.5 & $0.3-0.8$ \\
\hline I-TFA & 0.1 & $0.2-0.4$ & 0.1 & $0.0-0.4$ & 0.1 & $0.0-0.3$ \\
\hline R-TFA & 0.4 & $0.2-0.6$ & 0.4 & $0.2-0.6$ & 0.3 & $0.2-0.6$ \\
\hline \multicolumn{7}{|l|}{ Abdominal obesity } \\
\hline Waist $(\mathrm{cm})$ & 99.5 & $83 \cdot 5-128 \cdot 0$ & $91.5^{\star}$ & $81 \cdot 0-109 \cdot 0$ & 116.5 & $100 \cdot 0-136 \cdot 0$ \\
\hline $\mathrm{SAD}(\mathrm{cm})$ & $22 \cdot 8$ & $18 \cdot 0-31 \cdot 0$ & $20 \cdot 5^{\star}$ & $17 \cdot 4-25 \cdot 4$ & $27 \cdot 0$ & $21 \cdot 4-33 \cdot 3$ \\
\hline Truncal fat mass (\%) & $30 \cdot 1$ & $15 \cdot 7-41 \cdot 2$ & $24 \cdot 8^{*}$ & $13 \cdot 2-35 \cdot 8$ & $37 \cdot 0$ & $27 \cdot 8-44 \cdot 8$ \\
\hline \multicolumn{7}{|l|}{ Inflammation } \\
\hline $\mathrm{IL}-6(\mu \mathrm{g} / \mathrm{ml})$ & $16 \cdot 6$ & $8 \cdot 0-53 \cdot 3$ & $16 \cdot 3$ & $8 \cdot 0-54.4$ & $16 \cdot 7$ & $8 \cdot 0-47 \cdot 8$ \\
\hline C-reactive protein $(\mu \mathrm{g} / \mathrm{ml})$ & $1 \cdot 1$ & $0.3-9.9$ & $1.0^{*}$ & $0.2-8.8$ & 1.3 & $0.4-12 \cdot 2$ \\
\hline \multicolumn{7}{|l|}{ Blood lipids } \\
\hline Total cholesterol $(\mathrm{mmol} / \mathrm{l})$ & $5 \cdot 7$ & $4.5-7.0$ & $5 \cdot 7^{\star}$ & $4 \cdot 5-7 \cdot 2$ & $5 \cdot 5$ & $4 \cdot 3-6 \cdot 8$ \\
\hline TAG (mmol/l) & 1.3 & $0.7-2.7$ & $1 \cdot 2^{*}$ & $0.7-2 \cdot 3$ & 1.5 & $0.9-3.2$ \\
\hline LDL-cholesterol $(\mathrm{mmol} / \mathrm{l})$ & $3 \cdot 8$ & $2 \cdot 7-5 \cdot 0$ & 3.9 & $2 \cdot 7-5 \cdot 2$ & 3.6 & $2 \cdot 5-4 \cdot 8$ \\
\hline HDL-cholesterol $(\mathrm{mmol} / \mathrm{l})$ & $1 \cdot 1$ & $0.8-1.55$ & $1 \cdot 2^{*}$ & $0.9-1.6$ & 1.0 & $0.8-1.4$ \\
\hline Total:HDL-cholesterol ratio & 1.6 & $1 \cdot 2-2 \cdot 0$ & 1.6 & $1 \cdot 2-1 \cdot 9$ & 1.7 & $1 \cdot 3-2 \cdot 0$ \\
\hline \multicolumn{7}{|l|}{ Blood pressure $(\mathrm{mmHg})$} \\
\hline Systolic & 125 & $106-145$ & $122^{*}$ & $104-141$ & $127 \cdot 5$ & $111 \cdot 0-151 \cdot 0$ \\
\hline Diastolic & 78 & $66-91$ & $76^{*}$ & $65-89.5$ & $79 \cdot 2$ & $68 \cdot 5-92 \cdot 0$ \\
\hline \multicolumn{7}{|l|}{ Glucose homeostasis } \\
\hline HbA1c (\%) & $5 \cdot 6$ & $5 \cdot 3-6 \cdot 2$ & $5 \cdot 6$ & $5 \cdot 2-6 \cdot 0$ & 5.7 & $5 \cdot 3-6 \cdot 6$ \\
\hline Insulin sensitivity index & 5.5 & $2 \cdot 1-11 \cdot 7$ & $6 \cdot 8^{\star}$ & $3 \cdot 1-12 \cdot 8$ & 3.7 & $1.6-8.4$ \\
\hline \multicolumn{7}{|l|}{ LTPA (\%) } \\
\hline Almost passive & $10 \cdot 1$ & & 7.6 & & 13.5 & \\
\hline Light activity $(2-4 \mathrm{~h})$ & 51.9 & & 49.7 & & $55 \cdot 0$ & \\
\hline Light activity $(>4 \mathrm{~h})$ or medium $(2-4 \mathrm{~h})$ & 33.9 & & $39 \cdot 6$ & & $26 \cdot 2$ & \\
\hline Hard activity & $4 \cdot 0$ & & 3.2 & & $5 \cdot 2$ & \\
\hline Smokers (\%) & 39.8 & & $42 \cdot 0$ & & $36 \cdot 7$ & \\
\hline
\end{tabular}
(Median values with 10-90th percentiles)

TFA trans-fatty acids; I-TFA, industrially produced TFA; R-TFA, ruminant TFA; E\%, percentage of energy; SAD, sagittal abdominal diameter; LTPA, leisure-time physical activity.

*Values were significantly different from the corresponding median of the juvenile obese $(P<0.05)$. The difference in age is due to increasing prevalence of obesity over time during recruitment. 


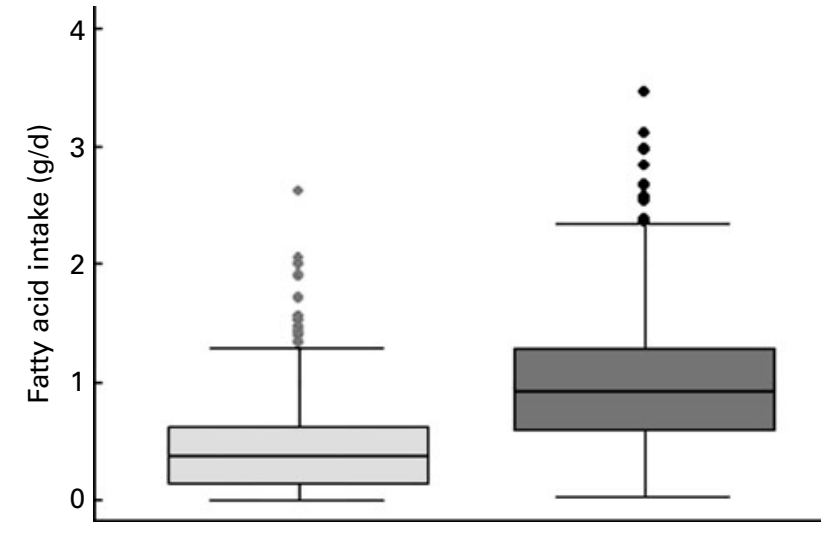

Fig. 1. Interquartile ranges (25-75th percentiles) and medians of industrial trans-fatty acid (I-TFA, $\square$ ) and ruminant trans-fatty acid (R-TFA, $\square$ ) intakes among middle-aged Danish men representing a broad range of BMI.

\section{Statistical analysis}

Characteristics of the participants are presented as medians with 10th and 90th percentiles. Associations between intake of total TFA, I-TFA and R-TFA $(\mathrm{g} / \mathrm{d})$ and each of the CHDrelated risk factors (abdominal fat distribution (WC, $n$ 384; percentage of truncal fat, $n$ 380)), proxies for intra-abdominal fat mass (WC for given BMI, $n$ 384; sagittal abdominal diameter, $n$ 379), inflammatory markers (IL-6, $n$ 379; C-reactive protein, $n$ 372), blood lipids (total cholesterol, $n$ 385; TAG, $n$ 371; LDL-cholesterol, $n$ 382; HDL-cholesterol, $n$ 383; total cholesterol:HDL-cholesterol, $n$ 383), blood pressure (systolic, $n$ 382; diastolic, $n$ 382) and glucose homeostasis (HbA1c, $n$ 376; insulin sensitivity index, $n$ 375) were analysed with linear regression models after testing for non-linearity in two-way scatterplots. $\beta$-Coefficients and 95\% CI were calculated and all analyses were carried out for the combined group representing the broad range of BMI, which according to the sampling design is allowable.

For examining the associations between TFA intake and the above-mentioned outcomes, three models were used. Model 1 is the raw model. Model 2 included total fat intake plus age, smoking status, leisure-time physical activity, alcohol and fibre intake. The total fat intake is included as we are interested in the effect of TFA, regardless of the intake of total fat. Model 3 included the same variables as model 2, with additional adjustment for intake of SFA and PUFA. I-TFA and R-TFA intakes were analysed in mutually adjusted models. Analyses of truncal fat mass and WC were rerun after additional adjustment for BMI.

Interactions between intake of TFA and the original sampling group were examined in all linear regression analyses and the distribution of residuals was investigated to ensure homogeneity in the data.

To investigate the potential influence of misreporting of dietary intake, all regression analyses and interaction between TFA and current BMI were rerun among those who were most likely to have reported an energy intake matching their energy expenditure ( $n$ 194, defined in an earlier study) ${ }^{(18)}$. Only minor differences from the results of the total group of men appeared, and thus misreporting did not seem to have had an influence on the results.

Data analyses were conducted using STATA statistical software, release 9.2 (STATA Corporation, College Station, TX, USA).

\section{Results}

The 393 men had a median age of 49 years and a median BMI of $28.4 \mathrm{~kg} / \mathrm{m}^{2}$ (10-90th percentile $22 \cdot 3-39 \cdot 5$ ), with $28.0 \%$ being normal weight, $31 \cdot 8 \%$ overweight and $40 \cdot 2 \%$ obese (Table 1). Most subjects were lightly physically active for $2-4 \mathrm{~h} /$ week $(51.9 \%)$ in their leisure time.

The median intake of total TFA was $1.3 \mathrm{~g} / \mathrm{d}$ (10-90th percentile $0 \cdot 6-2 \cdot 5)$, composed of $0.4 \mathrm{~g} / \mathrm{d}$ (10-90th percentile $0 \cdot 0-1 \cdot 0)$ of I-TFA and $0.9 \mathrm{~g} / \mathrm{d}(10-90$ th percentile $0 \cdot 4-1 \cdot 8)$ of $\mathrm{R}$-TFA. Interquartile ranges and medians of I-TFA and R-TFA intakes are illustrated in Fig. 1.

There were no associations between consumption of total TFA, I-TFA or R-TFA and abdominal obesity (waist), respectively, the proxies of intra-abdominal fat mass (waist for given BMI and sagittal abdominal diameter), nor with truncal fat mass (Table 2). No significant associations between intakes of TFA and pro-inflammatory markers, cholesterol levels, TAG and blood pressure were observed (Table 2). TFA intakes did not associate with the HbA1c level, whereas a tendency towards a positive association between R-TFA intakes and insulin sensitivity index was observed (model 3: $\beta 1 \cdot 14$, 95\% CI $-0 \cdot 13,2 \cdot 42$; Table 2).

Significant interactions between total TFA and the sampling group $(P=0.03)$ and between R-TFA and the sampling group $(P=0.02)$ were found for total cholesterol. These interactions may be attributed to multiple testing. No interactions between I-TFA intake and the sampling group were observed.

\section{Discussion}

In the present study of 393 middle-aged Danish men representing a broad range of BMI, low-to-moderate average intakes of TFA were not associated with abdominal fatness, pro-inflammatory markers, serum lipids, blood pressure or insulin homeostasis after adjustment for potential lifestyle confounders. This was the case when we examined total intake of TFA or separate intake of I-TFA and R-TFA.

The primary strength of the study was the availability of detailed clinical measurements and $7 \mathrm{~d}$ dietary records carried out in close proximity of each other from a unique sample of men representing a broad range of BMI and thereby a broad range of the obesity-related $\mathrm{CHD}$ risk markers of interest. According to the sampling fraction, the random sample represented 46400 draftees, whereas the juvenile obese group represented all obese individuals in the original draft board population. Analyses for interaction confirmed that pooling the groups was acceptable and did not bias the examined associations. A potential limitation to the study was the assessment of men only. However, although risk factors of CHD may differ between women and men ${ }^{(35)}$, epidemiological studies have not indicated that TFA should affect CHD risk differently 
Table 2. Associations between intake of trans-fatty acids (TFA) (industrially produced TFA (I-TFA) or ruminant TFA (R-TFA)) and risk factors of $\mathrm{CHD}$ among Danish men representing a broad range of $\mathrm{BMI}$

\begin{tabular}{|c|c|c|c|c|c|c|}
\hline & \multicolumn{2}{|c|}{ Total TFA (g/d) } & \multicolumn{2}{|c|}{ I-TFA (g/d) } & \multicolumn{2}{|c|}{ R-TFA (g/d) } \\
\hline & $\beta$ & $95 \% \mathrm{Cl}$ & $\beta$ & $95 \% \mathrm{Cl}$ & $\beta$ & $95 \% \mathrm{Cl}$ \\
\hline \multicolumn{7}{|c|}{ Abdominal obesity } \\
\hline \multicolumn{7}{|l|}{ Waist $(\mathrm{cm})^{*}$} \\
\hline Model $1^{\dagger}$ & -0.02 & $-0.04,0.00$ & -0.03 & $-0.07,0.01$ & 0.01 & $-0.03,0.05$ \\
\hline Model $2^{\dagger}$ & -0.01 & $-0.04,0.02$ & -0.03 & $-0.07,0.02$ & 0.00 & $-0.04,0.05$ \\
\hline Model $3^{\dagger}$ & -0.03 & $-0.06,0.01$ & -0.02 & $-0.07,0.03$ & -0.03 & $-0.08,0.02$ \\
\hline \multicolumn{7}{|c|}{ Waist $(\mathrm{cm})$ for given BMI $\left(\mathrm{kg} / \mathrm{m}^{2}\right)^{*}$} \\
\hline Model 1 & 0.00 & $-0.01,0.00$ & 0.00 & $-0.01,0.01$ & -0.01 & $-0.02,0.00$ \\
\hline Model 2 & 0.00 & $-0.01,0.01$ & 0.00 & $-0.01,0.02$ & -0.01 & $-0.02,0.01$ \\
\hline Model 3 & 0.00 & $-0.01,0.01$ & 0.00 & $-0.01,0.02$ & -0.01 & $-0.02,0.01$ \\
\hline \multicolumn{7}{|l|}{$\operatorname{SAD}(\mathrm{cm})^{*}$} \\
\hline Model 1 & -0.02 & $-0.05,0.02$ & -0.04 & $-0.09,0.01$ & 0.01 & $-0.04,0.06$ \\
\hline Model 2 & -0.02 & $-0.06,0.03$ & -0.04 & $-0.10,0.02$ & 0.01 & $-0.05,0.06$ \\
\hline Model 3 & -0.04 & $-0.08,0.01$ & -0.03 & $-0.09,0.03$ & -0.04 & $-0.11,0.02$ \\
\hline \multicolumn{7}{|c|}{ Truncal fat mass (\%) } \\
\hline Model 1 & -1.58 & $-2.80,-0.35$ & -2.65 & $-5.06,-0.23$ & $-1 \cdot 70$ & $-3.39,0.00$ \\
\hline Model 2 & -0.51 & $-2.42,1.40$ & -1.99 & $-4.74,0.76$ & 0.59 & $-1.82,2.99$ \\
\hline Model 3 & -1.41 & $-3.49,0.66$ & -1.57 & $-4 \cdot 31,1 \cdot 17$ & -1.23 & $-4 \cdot 16,1 \cdot 71$ \\
\hline \multicolumn{7}{|c|}{ Blood lipids } \\
\hline \multicolumn{7}{|c|}{ Total cholesterol $(\mathrm{mmol} / /)^{*}$} \\
\hline Model 1 & -0.01 & $-0.04,0.01$ & -0.03 & $-0.08,0.02$ & -0.01 & $-0.05,0.02$ \\
\hline Model 2 & 0.01 & $-0.03,0.04$ & 0.00 & $-0.06,0.05$ & 0.01 & $-0.04,0.06$ \\
\hline \multirow{2}{*}{\multicolumn{7}{|c|}{ TAG $(\mathrm{mmol} / \mathrm{l})^{*}$}} \\
\hline & & & & & & \\
\hline Model 1 & -0.06 & $-0.12,-0.06$ & -0.09 & $-0.20,0.02$ & -0.08 & $-0.16,0.00$ \\
\hline Model 2 & 0.01 & $-0.08,0.10$ & -0.01 & $-0.14,0.13$ & 0.02 & $-0.10,0.14$ \\
\hline Model 3 & 0.00 & $-0.10,0.10$ & -0.02 & $-0.11,0.15$ & -0.03 & $-0.17,0.11$ \\
\hline \multicolumn{7}{|c|}{ LDL-cholesterol $(\mathrm{mmol} / \mathrm{l})$} \\
\hline Model 1 & -0.02 & $-0.14,0.11$ & -0.09 & $-0.34,0.15$ & 0.02 & $-0.16,0.19$ \\
\hline Model 2 & 0.13 & $-0.07,0.34$ & 0.05 & $-0.24,0.34$ & 0.20 & $-0.06,0.45$ \\
\hline Model 3 & 0.15 & $-0.08,0.37$ & 0.08 & $-0.21,0.37$ & 0.22 & $-0.09,0.54$ \\
\hline HDL-cholest & & & & & & \\
\hline Model 1 & 0.00 & $-0.03,0.03$ & -0.01 & $-0.07,0.05$ & 0.01 & $-0.04,0.05$ \\
\hline Model 2 & -0.02 & $-0.07,0.03$ & -0.03 & $-0.10,0.04$ & -0.02 & $-0.08,0.04$ \\
\hline Model 3 & -0.02 & $-0.07,0.03$ & -0.03 & $-0.10,0.04$ & -0.01 & $-0.08,0.07$ \\
\hline Total:HDL-cl & & & & & & \\
\hline Model 1 & -0.01 & $-0.05,0.02$ & -0.02 & $-0.10,0.06$ & -0.02 & $-0.07,0.04$ \\
\hline Model 2 & 0.03 & $-0.04,0.09$ & 0.02 & $-0.07,0.11$ & 0.03 & $-0.05,0.11$ \\
\hline Model 3 & 0.03 & $-0.04,0.10$ & 0.03 & $-0.06,0.12$ & 0.02 & $-0.08,0.12$ \\
\hline Inflammation & & & & & & \\
\hline IL-6 ( $\mu \mathrm{g} / \mathrm{ml})$ & & & & & & \\
\hline Model 1 & 2.51 & $-0.70,5.72$ & -1.62 & $-7.95,4.70$ & 5.56 & $1.16,9.96$ \\
\hline Model 2 & $1 \cdot 11$ & $-4.13,6.35$ & -4.67 & $-12 \cdot 17,2 \cdot 82$ & 5.45 & $-1.15,12.04$ \\
\hline Model 3 & 0.90 & $-4.87,6.67$ & -3.78 & $-11 \cdot 31,3 \cdot 76$ & $6 \cdot 42$ & $-1.72,14.55$ \\
\hline C-reactive $p$ & & & & & & \\
\hline Model 1 & -0.39 & $-1.16,0.38$ & -0.66 & $-2.19,0.87$ & -0.41 & $-1.45,0.63$ \\
\hline Model 2 & -0.57 & $-1.79,0.65$ & -0.35 & $-2.13,1.44$ & -0.71 & $-2.23,0.80$ \\
\hline Model 3 & -0.44 & $-1.79,0.09$ & -0.25 & $-2.04,1.55$ & -0.65 & $-2.52,1 \cdot 21$ \\
\hline Blood pressure & & & & & & \\
\hline Systolic $(\mathrm{mm}$ & & & & & & \\
\hline Model 1 & -0.91 & $-3.04,1.22$ & -2.04 & $-6 \cdot 22,2 \cdot 14$ & -0.72 & $-3 \cdot 66,2 \cdot 22$ \\
\hline Model 2 & -1.38 & $-4.82,2.06$ & -2.28 & $-7.21,2.65$ & -0.70 & $-5.06,3.65$ \\
\hline Model 3 & -1.73 & $-5.51,2.05$ & -1.79 & $-6.75,3.18$ & -1.66 & $-6.99,3.67$ \\
\hline Diastolic (mr & & & & & & \\
\hline Model 1 & -1.02 & $-2.32,0.28$ & -1.34 & $-3.91,1.22$ & -1.28 & $-3.07,0.52$ \\
\hline Model 2 & -0.96 & $-3.07,1 \cdot 16$ & -1.09 & $-4.12,1.94$ & -0.85 & $-3.53,1.82$ \\
\hline Model 3 & -0.99 & $-3.32,1.33$ & -0.74 & $-3 \cdot 79,2 \cdot 31$ & -1.29 & $-4.57,1.98$ \\
\hline Glucose home & & & & & & \\
\hline $\mathrm{HbA1c}(\%)^{*}$ & & & & & & \\
\hline Model 1 & 0.00 & $-0.02,0.01$ & -0.02 & $-0.04,0.01$ & 0.00 & $-0.02,0.02$ \\
\hline Model 2 & 0.00 & $-0.02,0.02$ & -0.02 & $-0.05,0.01$ & 0.01 & $-0.01,0.04$ \\
\hline Model 3 & -0.01 & $-0.03,0.02$ & -0.01 & $-0.04,0.02$ & 0.00 & $-0.03,0.04$ \\
\hline Insulin sensi & & & & & & \\
\hline Model 1 & 0.40 & $-0.13,0.93$ & 0.47 & $-0.56,1.51$ & 0.53 & $-0.20,1.26$ \\
\hline Model 2 & 0.40 & $-0.42,1.22$ & 0.46 & $-0.73,1.65$ & 0.35 & $-0.69,1.40$ \\
\hline Model 3 & 0.68 & $-0.22,1.58$ & 0.27 & $-0.91,1.47$ & $1 \cdot 14$ & $-0.13,2.42$ \\
\hline
\end{tabular}

SAD, sagittal abdominal diameter.

* Log-transformed.

${ }^{\dagger}$ Model 1, unadjusted; model 2, adjusted for total fat intake ( $\mathrm{g} / \mathrm{d}$ ), age (years), leisure-time physical activity (almost passive, light activity $2-4 \mathrm{~h}$, light activity $>4 \mathrm{~h}$ or medium $2-4 \mathrm{~h}$ and hard activity), smoking status (yes or no), alcohol intake ( $\mathrm{g} / \mathrm{d}$ ) and fibre intake ( $\mathrm{g} / \mathrm{d}$ ), and mutually adjusted for R-TFA and I-TFA, respectively; model 3 (same as model 2) and additional adjustment for intake of SFA (g/d) and PUFA (g/d). 
in women and men and thereby compromise the generalisability of the present findings ${ }^{(36,37)}$. Still, we cannot rule out that the results from the present study may not transfer directly to women. Another potential limitation could be imprecise dietary measurement or dietary under-reporting. The use of a dietary record should diminish the risk of recall bias, but instead people might change their habitual intake, intentionally or unintentionally, during the reporting period. However, as long as such uncertainties are equally distributed throughout the study population, estimates may be weakened and hence conservative, but they should not be confounded. Misreporting is a main error in dietary research, but our analyses showed no difference between results of the total group of subjects and when excluding the most likely misreporters of energy intake.

Uncertainties in estimating actual dietary intake of TFA may exist. Since rather few products contained I-TFA at the time of data collection, it is likely that the standardised dietary record, which was not specifically designed for obtaining detailed information on TFA intake, may have led to lower estimated intake than the actual intake. Although the content of I-TFA in the distinct food items may have errors, the estimation benefits from the thorough analysis of a variety of Danish food items at time points close to the dietary assessment.

Misreporting and the approximation of TFA in food items are thus not believed to have biased the association between TFA and the clinical outcomes substantially.

In the present study, the average intakes of TFA and I-TFA were relatively low $(1.3 \mathrm{~g} / \mathrm{d}, 10-90$ th percentile $0.6-2.5 \mathrm{~g} / \mathrm{d}$; $0.4 \mathrm{~g} / \mathrm{d}, 10-90$ th percentile $0.0-1 \cdot 0)$ compared with former epidemiological studies reporting an increased risk of $\mathrm{CHD}$ following intake of TFA ${ }^{(36,37)}$. Total TFA intake has previously been found to range from about $1.5 \mathrm{~g}$ in Greece and Italy to $5.4 \mathrm{~g}$ in Ireland ${ }^{(38)}$. Intake of R-TFA in the present study was also lower than that in some former studies ${ }^{(39,40)}$.

Associations between I-TFA and markers of abdominal obesity (WC and percentage of truncal fat) and of the proxies of intra-abdominal obesity (sagittal abdominal diameter and WC for given BMI) tended to be negative, although applied measuring methods are found to correlate well with intraabdominal fat ${ }^{(41,42)}$, which is suggested to be the most harmful fat deposit from a metabolic perspective ${ }^{(42)}$. To our knowledge, only a few epidemiological studies have formerly assessed TFA intake in relation to abdominal fat accumulation - with poorer measures of intra-abdominal fat - and the findings have been contradictive ${ }^{(43,44)}$. A former study in human subjects has reported a significant but small waist gain of $0.77 \mathrm{~cm} / 2 \%$ increment in energy intake from any TFA source $^{(43)}$. Similarly, TFA intake tended to increase WC more than a control fat in healthy overweight postmenopausal women, while the deposition of abdominal and liver fat did not differ ${ }^{(7)}$. A randomised controlled trial in monkeys showed that a 6-year-long I-TFA-rich diets (approximately 8\% of energy) resulted in a significant increase in intra-abdominal fat mass $^{(6)}$. Since energy intake was controlled in the latter trial, authors have concluded that TFA consumption might affect metabolism and adipogenesis. However, well-documented biological mechanisms behind the potential abdominal obesity-inducing effect of TFA are lacking. The difficulties in extrapolating from animal experiments to human subjects and the fact that the intake of I-TFA in the trial on monkey was extremely high compared with assumed average intake in populations may explain why the cited results were not confirmed in the present paper.

In the present study, no clear associations between TFA and levels of IL-6 or C-reactive protein were found. The findings conflict with the evidence from observational studies indicating that TFA consumption increases the levels of the pro-inflammatory markers IL-6 and C-reactive protein among overweight women $^{(45,46)}$. Further studies within this area are warranted, but the cited literature and the present findings may suggest that TFA primarily induces inflammation in already obese individuals with high TFA intake.

The most well-documented effect of I-TFA on CHD risk markers is the effect on serum lipids ${ }^{(1)}$. In the present study, the relatively low I-TFA intake was not associated with lipid levels. In contrast, a meta-analysis of controlled trials - with I-TFA intakes ranging from 0.0 to $10.9 \%$ of total energy found a negative impact on cholesterol homeostasis ${ }^{(4)}$. Similarly, in a prospective observational study, increasing TFA intake (mean intake $3.0 \mathrm{~g} / \mathrm{d}$ ) was associated with an increase in LDL-cholesterol and a decrease in HDL-cholesterol levels ${ }^{(47)}$. In the present study, R-TFA was not associated with serum lipids either. Consistent with this, two recent cross-over, randomised, controlled trials demonstrated that high levels of R-TFA (approximately $10 \mathrm{~g} / \mathrm{d}$ ) affect cholesterol homeostasis negatively, whereas moderate intakes had neutral effects $^{(10,11)}$.

We found no association between intake of TFA of either source and systolic and diastolic blood pressure, in accordance with former intervention studies of even higher intake $^{(48,49)}$.

Also, no association with HbA1c was observed, whereas a trend towards a positive association between R-TFA and insulin sensitivity index was seen. A very high intake of TFA has formerly been demonstrated to affect insulin sensitivity in short-term trials of obese subjects with or without diabetes $^{(50-52)}$, whereas lower intake of TFA intake was not associated with insulin resistance among abdominal obese women $^{(53)}$, overweight men and women ${ }^{(54)}$ or healthy subjects $^{(55)}$. Epidemiological data on the risk of type 2 diabetes in human subjects following a high intake of TFA are conflicting ${ }^{(50,56-59)}$. In monkeys, Kavanagh et al. ${ }^{(6)}$ demonstrated that high TFA consumption for 6 years changed insulin sensitivity through impaired glucose disposal. Potentially, both level and duration of TFA exposure and underlying predisposition to insulin resistance influence the effect of TFA on glucose homeostasis.

In conclusion, our cross-sectional study on healthy men representing a broad range of BMI suggests that variation around a relatively low contribution of TFA to energy intake is not associated with a panel of cardiovascular risk markers - in contrast to earlier findings from high-dose intervention trials of selected subpopulations. We hypothesise that the level and duration of TFA intake as well as the individual's health stage influence the effect of TFA on risk markers of 
CHD and that the out-phasing of I-TFA in Denmark has had a positive impact on health at the population level. Future studies from countries where similar restrictions are introduced should assess this hypothesis.

\section{Acknowledgements}

The present study was carried out as part of the research programme of the Danish Obesity Research Centre (DanORC, see www.danorc.dk). DanORC is supported by the Danish Council for Strategic Research (grant no. 2101-06-0005). The authors declare that they have no conflicts of interest in relation to the present study. T. I. A. S. initiated, designed, coordinated and, among others, conducted the initial draft board study and the follow-up studies. A. A. and T. I. A. S. conceived the present follow-up examination. The present study was initiated by T. J. in collaboration with M. U. J. and T. I. A. S.; M. M. N. and C. J. N. examined the dietary data and program for errors and conducted the initial analyses; M. M. N performed further analyses under the supervision of C. H.; M. U. J., T. I. A. S. and T. J. helped to interpret the results; M. M. N. drafted the manuscript, which was further edited by all co-authors and finished by B. M. N.; M. M. N. and T. J. have the primary responsibility for the final content. All authors contributed to and accepted the final manuscript. We thank Dr Eva Black, $\mathrm{PhD}$ for her assistance in collection of the follow-up data and professor Berit L. Heitmann is thanked for her valuable inputs through the conduct of the present study. B. M. N. and M. M. N. contributed equally to this work.

\section{References}

1. Micha R \& Mozaffarian D (2008) Trans fatty acids: effects on cardiometabolic health and implications for policy. Prostaglandins Leukot Essent Fatty Acids 79, 147-152.

2. Stender S, Dyerberg J, Bysted A, et al. (2006) A trans world journey. Atheroscler Suppl 7, 47-52.

3. Erkkila A, de Mello VD, Riserus U, et al. (2008) Dietary fatty acids and cardiovascular disease: an epidemiological approach. Prog Lipid Res 47, 172-187.

4. Mensink RP, Zock PL, Kester AD, et al. (2003) Effects of dietary fatty acids and carbohydrates on the ratio of serum total to HDL cholesterol and on serum lipids and apolipoproteins: a metaanalysis of 60 controlled trials. Am J Clin Nutr 77, 1146-1155.

5. Mensink RP (2005) Metabolic and health effects of isomeric fatty acids. Curr Opin Lipidol 16, 27-30.

6. Kavanagh K, Jones KL, Sawyer J, et al. (2007) Trans fat diet induces abdominal obesity and changes in insulin sensitivity in monkeys. Obesity (Silver Spring) 15, 1675-1684.

7. Bendsen NT, Chabanova E, Thomsen HS, et al. (2011) Effect of trans fatty acid intake on abdominal and liver fat deposition and blood lipids - a randomized trial in overweight postmenopausal women. Metabolism (Epublication ahead of print version 10 March 2011).

8. Ghafoorunissa G (2008) Role of trans fatty acids in health and challenges to their reduction in Indian foods. Asia Pac J Clin Nutr 17, Suppl. 1, 212-215.

9. Stender S, Astrup A \& Dyerberg J (2008) Ruminant and industrially produced trans fatty acids: health aspects. Food Nutr Res (Epublication ahead of print version 12 March 2008).
10. Chardigny JM, Destaillats F, Malpuech-Brugere C, et al. (2008) Do trans fatty acids from industrially produced sources and from natural sources have the same effect on cardiovascular disease risk factors in healthy subjects? Results of the trans Fatty Acids Collaboration (TRANSFACT) study. Am J Clin Nutr 87, 558-566.

11. Motard-Belanger A, Charest A, Grenier G, et al. (2008) Study of the effect of trans fatty acids from ruminants on blood lipids and other risk factors for cardiovascular disease. $\mathrm{Am}$ J Clin Nutr 87, 593-599.

12. Mensink RP \& Nestel P (2009) Trans fatty acids and cardiovascular risk markers: does the source matter? Curr Opin Lipidol 20, 1-2.

13. Bysted A, Mikkelsen A \& Leth T (2009) Substitution of trans fatty acids in foods on the Danish market. Eur J Lipid Sci Technol 111, 574-583.

14. Christensen U, Sonne-Holm S \& Sorensen TI (1981) Constant median body mass index of Danish young men, 1943-1977. Hum Biol 53, 403-410.

15. Sonne-Holm S \& Sorensen TI (1977) Post-war course of the prevalence of extreme overweight among Danish young men. J Chronic Dis 30, 351-358.

16. Sorensen TI \& Sonne-Holm S (1977) Mortality in extremely overweight young men. J Chronic Dis 30, 359-367.

17. Black E, Holst C, Astrup A, et al. (2005) Long-term influences of body-weight changes, independent of the attained weight, on risk of impaired glucose tolerance and type 2 diabetes. Diabet Med 22, 1199-1205.

18. Nielsen BM, Nielsen MM, Toubro S, et al. (2009) Past and current body size affect validity of reported energy intake among middle-aged Danish men. J Nutr 139, 2337-2343.

19. Hansen K, Knuthsen P \& Saxholt E (2001) Nutritional Content of Chips. Foedevare Rapport no. 2001:4. Soeborg: Danish Veterinary and Food Administration.

20. Leth T, Bysted A, Hansen K, et al. (2003) Trans FA content in Danish margarines and shortenings. J Am Oil Chem Soc $\mathbf{8 0}$ 475-478.

21. Mikkelsen AA \& Leth T (2003) Trans Fatty Acid Content of Selected Foods. Foedevare Rapport no. 2003:11. Soeborg: Danish Veterinary and Food Administration.

22. Stender S \& Dyerberg J (2003) The Influence of Trans Fatty Acids on Health no. 34. Copenhagen: The Danish Nutrition Council.

23. van Poppel G (1998) Intake of trans fatty acids in western Europe: The TRANSFAIR study. Lancet 351, 1099-1099.

24. Jakobsen MU, Bysted A, Andersen NL, et al. (2006) Intake of ruminant trans fatty acids and risk of coronary heart disease - an overview. Atheroscler Suppl 7, 9-11.

25. Leth T, Ovesen L \& Hansen K (1998) Fatty acid composition of meat from ruminants, with special emphasis on trans fatty acids. J Am Oil Chem Soc 75, 1001-1005.

26. Black E, Petersen L, Kreutzer M, et al. (2002) Fat mass measured by DXA varies with scan velocity. Obes Res 10, 69-77.

27. World Health Organization (1995) Physical Status: the Use and Interpretation of Anthropometry. Report of a WHO Expert Committee. WHO Technical Report Series no. 854. Geneva: WHO.

28. Buemann B, Sorensen TIA, Pedersen O, et al. (2005) Lowerbody fat mass as an independent marker of insulin sensitivity - the role of adiponectin. Int J Obes (Lond) 29, 624-631.

29. World Health Organization (2000) Obesity: Preventing and Managing the Global Epidemic. Report of a WHO consultation. WHO Technical Report Series no. 894. Geneva: WHO.

30. Friedewald WT, Levy RI \& Fredrickson DS (1972) Estimation of the concentration of low-density lipoprotein cholesterol in 
plasma, without use of the preparative ultracentrifuge. Clin Chem 18, 499-502.

31. Skogstrand K, Ekelund CK, Thorsen P, et al. (2008) Effects of blood sample handling procedures on measurable inflammatory markers in plasma, serum and dried blood spot samples. J Immunol Methods 336, 78-84.

32. Skogstrand K, Thorsen P, Norgaard-Pedersen B, et al. (2005) Simultaneous measurement of 25 inflammatory markers and neurotrophins in neonatal dried blood spots by immunoassay with xMAP technology. Clin Chem 51, 1854-1866.

33. WHO (1999) Definition, Diagnosis and Classification of Diabetes Mellitus and its Complications. Report of a WHO consultation. Part 1: Diagnosis and Classification of Diabetes Mellitus. Geneva: WHO.

34. Matsuda M \& DeFronzo RA (1999) Insulin sensitivity indices obtained from oral glucose tolerance testing: comparison with the euglycemic insulin clamp. Diabetes Care 22, 1462-1470.

35. Silander K, Alanne M, Kristiansson K, et al. (2008) Gender differences in genetic risk profiles for cardiovascular disease. PLoS One 3, e3615.

36. Oh K, Hu FB, Manson JE, et al. (2005) Dietary fat intake and risk of coronary heart disease in women: 20 years of followup of the nurses' health study. Am $J$ Epidemiol 161, 672-679.

37. Oomen CM, Ocke MC, Feskens EJ, et al. (2001) Association between trans fatty acid intake and 10-year risk of coronary heart disease in the Zutphen Elderly Study: a prospective population-based study. Lancet 357, 746-751.

38. Hulshof KF, van Erp-Baart MA, Anttolainen M, et al. (1999) Intake of fatty acids in western Europe with emphasis on trans fatty acids: the TRANSFAIR study. Eur J Clin Nutr 53, $143-157$

39. Jakobsen MU, Overvad K, Dyerberg J, et al. (2008) Intake of ruminant trans fatty acids and risk of coronary heart disease. Int J Epidemiol 37, 173-182.

40. Willett WC, Stampfer MJ, Manson JE, et al. (1993) Intake of trans fatty acids and risk of coronary heart disease among women. Lancet 341, 581-585.

41. Park YW, Heymsfield SB \& Gallagher D (2002) Are dualenergy X-ray absorptiometry regional estimates associated with visceral adipose tissue mass? Int J Obes (Lond) $\mathbf{2 6}$, 978-983.

42. Pouliot MC, Despres JP, Lemieux S, et al. (1994) Waist circumference and abdominal sagittal diameter: best simple anthropometric indexes of abdominal visceral adipose tissue accumulation and related cardiovascular risk in men and women. Am J Cardiol 73, 460-468.

43. Koh-Banerjee P, Chu NF, Spiegelman D, et al. (2003) Prospective study of the association of changes in dietary intake, physical activity, alcohol consumption, and smoking with 9-y gain in waist circumference among 16587 US men. Am J Clin Nutr 78, 719-727.

44. Merchant AT, Anand SS, Vuksan V, et al. (2005) Protein intake is inversely associated with abdominal obesity in a multi-ethnic population. J Nutr 135, 1196-1201.
45. Lopez-Garcia E, Schulze MB, Meigs JB, et al. (2005) Consumption of trans fatty acids is related to plasma biomarkers of inflammation and endothelial dysfunction. J Nutr 135, 562-566.

46. Mozaffarian D, Pischon T, Hankinson SE, et al. (2004) Dietary intake of trans fatty acids and systemic inflammation in women. Am J Clin Nutr 79, 606-612.

47. Sun Q, Ma J, Campos H, et al. (2007) A prospective study of trans fatty acids in erythrocytes and risk of coronary heart disease. Circulation 115, 1858-1865.

48. Mensink RP, de Louw MH \& Katan MB (1991) Effects of dietary trans fatty acids on blood pressure in normotensive subjects. Eur J Clin Nutr 45, 375-382.

49. Raff M, Tholstrup T, Sejrsen K, et al. (2006) Diets rich in conjugated linoleic acid and vaccenic acid have no effect on blood pressure and isobaric arterial elasticity in healthy young men. J Nutr 136, 992-997.

50. Lefevre M, Lovejoy JC, Smith SR, et al. (2005) Comparison of the acute response to meals enriched with cis- or trans-fatty acids on glucose and lipids in overweight individuals with differing FABP2 genotypes. Metabolism 54, 1652-1658.

51. Vega-Lopez S, Ausman LM, Jalbert SM, et al. (2006) Palm and partially hydrogenated soybean oils adversely alter lipoprotein profiles compared with soybean and canola oils in moderately hyperlipidemic subjects. Am J Clin Nutr 84, 54-62.

52. Christiansen E, Schnider S, Palmvig B, et al. (1997) Intake of a diet high in trans monounsaturated fatty acids or saturated fatty acids - effects on postprandial insulinemia and glycemia in obese patients with NIDDM. Diabetes Care 20, 881-887.

53. Tardy AL, Lambert-Porcheron S, Malpuech-Brugere C, et al. (2009) Dairy and industrial sources of trans fat do not impair peripheral insulin sensitivity in overweight women. Am J Clin Nutr 90, 88-94.

54. Lovejoy JC, Champagne CM, Smith SR, et al. (2001) Relationship of dietary fat and serum cholesterol ester and phospholipid fatty acids to markers of insulin resistance in men and women with a range of glucose tolerance. Metabolism $\mathbf{5 0}$, $86-92$.

55. Lovejoy JC, Smith SR, Champagne CM, et al. (2002) Effects of diets enriched in saturated (palmitic), monounsaturated (oleic), or trans (elaidic) fatty acids on insulin sensitivity and substrate oxidation in healthy adults. Diabetes Care 25, 1283-1288.

56. Hu FB, Manson JE, Stampfer MJ, et al. (2001) Diet, lifestyle, and the risk of type 2 diabetes mellitus in women. $N$ Engl $J$ Med 345, 790-797.

57. Meyer KA, Kushi LH, Jacobs DR, et al. (2001) Dietary fat and incidence of type 2 diabetes in older Iowa women. Diabetes Care 24, 1528-1535.

58. Salmeron J, Hu FB, Manson JE, et al. (2001) Dietary fat intake and risk of type 2 diabetes in women. Am J Clin Nutr 73, 1019-1026.

59. van Dam RM, Willett WC, Rimm EB, et al. (2002) Dietary fat and meat intake in relation to risk of type 2 diabetes in men. Diabetes Care 25, 417-424. 